\title{
Evaluation the Effect of Intrathecally Fentanyl Added to Lidocaine on Interception of Shivering in Abdominal Hysterectomy: Randomized Clinical Trial
}

\author{
Maziar Mahjoubifard, ${ }^{1}$ Masoomeh Nataj-Majd, ${ }^{2,}$ Somaye Sadat Heidary, ${ }^{3}$ and Nariman Mahjoubifard ${ }^{4}$ \\ ${ }^{1}$ Assistant Professor of Anesthesiology, Cardiac Anesthesia Fellowship, Children and Adolescent Health Research Center, Ali-Ebne- Abitaleb Hospital, Zahedan University of \\ Medical Sciences, Zahedan, IR Iran \\ ${ }^{2}$ Arash Women's Hospital, Tehran University of Medical Sciences, Tehran, IR Iran \\ ${ }^{3} \mathrm{PhD}$ Student, Clinical Biochemistry Department, Hamadan University of Medical Sciences, Hamadan, IR Iran \\ ${ }^{4}$ Pre University Graduate, Zahedan, IR Iran \\ "Corresponding author: Masoomeh Nataj-Majd, Arash Women's Hospital, Tehran University of Medical Sciences, Tehran, IR Iran. Tel: +98-2177883283, Fax: +98-2177883196, E-mail: \\ m-nataj@farabi.tums.ac.ir
}

Received 2016 September 03; Revised 2016 November 16; Accepted 2017 January 09.

\begin{abstract}
Background: Shivering is a frequent phenomenon in postoperative period. Post spinal shivering causes a major distress for patients and may induce some complications. Investigations to control shivering could not mange it completely.

Objectives: The aim of this randomized single-blind study was to investigate how much the high dose (50 $\mu \mathrm{g})$ of intrathecally administered fentanyl would influence the incidence and severity of shivering in patients undergoing abdominal hysterectomy. Methods: In this prospective clinical trial, seventy healthy patients scheduled for abdominal hysterectomy under spinal anesthesia using $75 \mathrm{mg}$ of hyperbaric 5\% lidocaine were randomly allocated to receive an additional $50 \mu \mathrm{g}(1 \mathrm{~mL})$ of fentanyl intrathecally (group F) or normal saline $1 \mathrm{~mL}$ (groups).Then the level of shivering was measured with crossly and mahajon scale and analyzed with chi-square test using SPSS version 17 software.

Results: The incidence of shivering up to two hours after spinal anesthesia was 13 from 35 patients (37.2\%) in group F, and 27 from 35 patients (77.2\%) in group S. The difference was statistically significant $(\mathrm{P}<0.01)$. The shivering score was significantly lower in group F. There was no difference in the incidence of pharmacologic side effects.

Conclusions: Addition of $50 \mu \mathrm{g}$ fentanyl to $75 \mathrm{mg}$ of hyperbaric $5 \%$ lidocaine intrathecally can reduce the incidence and severity of shivering in patients who receive abdominal hysterectomy without increasing other side effects.
\end{abstract}

Keywords: Fentanyl, Lidocaine, Shivering, Hysterectomy

\section{Introduction}

Thermoregulation in warm-blooded species (homoeothermic) is a process that allows the body to maintain its normal temperature. This condition in homoeothermic species, having an even internal temperature, is called homeostasis. All thermoregulation mechanisms are designed to return the body to homeostasis. A normal and safe temperature has a very narrow window - between $37^{\circ} \mathrm{C}$ and $37.8^{\circ} \mathrm{C}$ [1]. Within a few degrees of this narrow range, body may experience signs that show the body temperature is changing. Researches show that hypothermia is common during deep sedation or general anesthesia and is frequently affiliated with patient discomfort and shivering [2]. Hypothermia during anesthesia is a common per operative thermal disturbance and patients lose heat primarily from the skin to the environment through several processes.

When patient's brain receives a temperature warning from their body, it sends signals to various organs and body systems, which try to slow or increase heat production and the result will be coetaneous vasodilatation, vasoconstriction, sweating and shivering. With The drop in core temperature, patients may become hypothermic enough to commence shivering. The concomitant use of sedation not only compounds the depression of thermoregulation but obtunds the patient's subjective sensations. Shivering is the body's defense when behavioral compensation, maximal arteriovenous shunt and vasoconstriction fail to maintain the core temperature [3]. Shivering which is oscillatory muscular activity that rise up the metabolic heat production, happens as a main complication of hypothermia between $40 \%$ to $60 \%$ of volatile Inhalational anesthetics. Shivering happens about $30 \%$ in patients with a core temperature of $35.5^{\circ} \mathrm{C}$ and about $90 \%$ with body temperature of $34.5^{\circ} \mathrm{C}$. These consequences are directly related to the duration of operation and also the condensation of volatile anesthetic $[1,4,5]$. Although it occurs frequently, it remains poorly understood. 
Main factors that can cause shivering are young age, endoprosthetic operation and core hypothermia. Shivering can double up the oxygen consumption and carbon dioxide production up to $200 \%$ which causes adverse myocardial outcomes in high risks cases and increase the metabolic heat production up to $60 \%$. Hyperthermia (38 $-39^{\circ} \mathrm{C}$ ), metabolic acidosis, increases intraocular and intracranial pressures, incidental trauma, disrupts medical devices, and interferes with electrocardiography and pulse oximetry monitoring are the consequences of shivering [2, $5,6]$.

It is vital to all shivering cases to be prevented, thereby counteract hypothermia. If shivering does occur, it can be treated by warming up the skin surface since skin temperature contributes to control of thermoregulatory responses. In most cases from moderate to severe pharmacologic treatments are needed to stop shivering. The drugs, opioids, that is effective for treating shivering after general anesthesia include meperidine, alfentanil, fentanyl, and morphine [3].

Considering some side effect of intravenous drugs for management of shivering [1], today the main focus is to prevent shivering by injecting substances that act on opioid receptors to produce morphine-like effects into the subarachnoid space, interval between the arachnoid membrane and the pia mater. The most common case that this prevention can be used is $C / S$ (cesarean section) since shivering causes intensive discomfort for patients [1].

The aim of our study was to review perioperative temperature monitoring and the effects of intrathecally anesthetic drugs, $50 \mu \mathrm{g}(1 \mathrm{~mL})$ fentanyl, on preventing shivering in abdominal hysterectomy undergoing by spinal anesthesia.

\section{Methods}

This prospective randomized clinical trial was performed in Zahedan, Ali Ebn-e Abitaleb from June 2014 to February 2015. This clinical trial approved by the institutional review board and the ethics committee of Tehran University of Medical Sciences, Tehran, Iran and, submitted in Iranian registry of clinical trial with the number of IRCT2015022416162N2.

Inclusion criteria were as follow: all patients who were candidate for abdominal hysterectomy, age between 35 - 55 years, with American society of anesthesiologist's classification I and II.

Exclusion criteria was as follow: allergy or intolerance to amid-type local anesthetics, cancer, obesity (body mass index $30 \mathrm{~kg} / \mathrm{m}^{2}$ ), contraindication to a spinal puncture (coagolopathy, infection in the spinal site and patient refuse) addiction to narcotics, sedatives or any medication likely to alter thermoregulation.

To have an $80 \%$ power to detect 36 percent difference in the primary outcome (Shivering) between two groups as significant (at the 2-sided 5\% level), 35 subjects in each group were required.

\subsection{Randomization}

Informed consent was obtained from all patients and they randomly allocated into two equal groups (35 patients in each group). Randomization was done using a random number sequence with a computer-generated randomization scheme with block size of six. Concealment procedure was maintained with numbered cards in sealed envelopes. Envelopes were prepared by an epidemiologist who was not involved in the allocation of patients. As the author open a numbered envelope, patients were allocated into one of two treatments.

All patients were monitored by pulse oximetry, noninvasive blood pressure measuring device and doing continuous electrocardiography (SAZGAN, model VectRA, Iran) before starting the procedure of surgery. Venous access was obtained in upper limb with a $20 \mathrm{G}$ catheter. Intra venous fluids in the form of lactated ringer's solution were infused at rate of $15 \mathrm{cc} / \mathrm{kg} / \mathrm{h}$. Fluids were not warm (room temperature). The ambient temperature was maintained at $22-24^{\circ} \mathrm{C}$. Lumbar puncture was performed at L3-L4 with a 25G Quincke (B.Braun Germany) spinal needle. A combination of $75 \mathrm{mg}$ of hyperbaric 5\% lidocaine with $50 \mu \mathrm{g}(1$ $\mathrm{mL}$ ) fentanyl (group F) or $1 \mathrm{~mL}$ normal saline (group S), was administered intrathecally.

All patients were placed in the supine position. Supplemental oxygen was given via a facemask at rate of $5 \mathrm{lit} / \mathrm{min}$ during the operation.

When spinal anesthesia was established with pin prick test, the surgeon started the operation. All operations were performed with the same surgeon. After the initiation of surgery, presence of shivering was observed and recorded as the primary outcome and , shivering was graded by using Crossland Mahajon Scale as the secondary outcome as follow:

\section{$0=$ no shivering}

$1=$ piloerection or peripheral vasoconstriction but no visible shivering.

$2=$ muscular activity in only one muscle group.

$3=$ muscular activity in more than one muscle group but not generalized.

4 = shivering all over the body.

The evaluation was done by an investigator blinded to the patient's group allocation every 5 minutes during surgery and at recovery room for two hours. If shivering occurred, it was recorded and graded and if the grade was 
3 or 4 , it was considered sever shivering and rescue treatment in the form of $25 \mathrm{mg}$ of IV meperidine was given.

For treatment of symptomatic or non-symptomatic hypotension (SBP $<30 \%$ from baseline or less than 80 $\mathrm{mmHg}$ ), bolus of fluid and incremented dose of 5 - $10 \mathrm{mg}$ ephedrine was used.

If patients reported pain during the surgery, bolus dose of $50-100 \mu \mathrm{g}$ fentanyl was administered and the patients were excluded from the study. Tympanic membrane temperature were recorded every 20 minutes during and post of anesthesia up to two hours. $4 \mathrm{mg}$ ondansetron was used intravenously to treat nausea and vomiting. The flowchart of participants and group division has been shown in Figure 1.

\subsection{Statistical Analysis}

The differences between quantitative variables in groups were analyzed with chi-square test using SPSS software version 17 .

\section{Results}

Seventy women were recruited to this study: There were no significant differences in age, BMI, surgical time, height of sensory black or body temperature between the two groups prior to anesthesia (Table 1).

Table 1. Demographic Data and Baseline Variables ${ }^{\mathrm{a}}$

\begin{tabular}{|c|c|c|c|}
\hline Variables & Group $F(n=35)$ & Group $S(n=35)$ & PValue \\
\hline Age, $y$ & $44.9 \pm 8.2$ & $41.7 \pm 7.7$ & 0.097 \\
\hline BMI & $28.83 \pm 8.7$ & $29.13 \pm 9.1$ & 0.888 \\
\hline Surgery time, min & $60 \pm 35$ & $62 \pm 41$ & 0.826 \\
\hline $\begin{array}{l}\text { Highest segment } \\
\text { blocked median, } \\
\text { range }\end{array}$ & T9 (T8 to T10) & T9 (T7 to T10) & 0.273 \\
\hline $\begin{array}{l}\text { Baseline temperature, } \\
{ }^{\circ} \mathrm{C}\end{array}$ & $36.2 \pm 0.3$ & $36.3 \pm 0.3$ & 0.167 \\
\hline
\end{tabular}

${ }^{\mathrm{a}}$ Values are expressed as mean $\pm \mathrm{SD}$.

We had totally 30 patients (42.9\%) without shivering and 40 patients (57.1\%) with some degree of shivering. In the latter group, we observed one patient with grade 1 , one patient with grade 2 , seven patients with grade 3 and 31 patients with grade 4 of shivering.

In fentanyl + lidocaine group, 13 patients (37.2\%) and in- lidocaine group alone, 27 patients (77.2\%) had shivering. the difference was statistically significant (P 0.001).(

These results illustrate that there is a significant difference in the intensity of shivering between the two groups $(\mathrm{P}<0.001)($
Table 2. Incidence of Shivering

\begin{tabular}{lccc}
\hline Variable & \multicolumn{2}{c}{ Groups } & \multirow{2}{*}{ P Value } \\
\cline { 2 - 3 } & Lidocaine & Lidocaine + Fentanyl & \\
\hline Have shivering & $27(77 / 2)$ & $13(37 / 2)$ & \\
Not shivering & $8(22 / 8)$ & $22(62 / 8)$ & $<0.001$ \\
\hline Total & $35(100)$ & $35(100)$ & \\
\hline${ }^{2}$ Values are expressed as No. (\%). & & \\
\end{tabular}

The incidence of spinal adverse effect was not statistically significant between two groups by fisher test $(\mathrm{P}<$ 0.059) (Table 3).

\section{Discussion}

The most important finding of this study was the $40 \%$ reduction in the incidence of shivering after abdominal hysterectomy with the administration of intrathecal fentanyl $50 \mu \mathrm{g}(1 \mathrm{~mL})$.

Shivering is a frequent complication in the postoperative period that may occur as an adverse effect of surgery and anesthesia.

Shivering increases metabolic heat production. In addition to heat rising, there is marked increase in oxygen consumptions and carbon dioxide production with potential risk of complications in patient with cardiovascular or pulmonary impairment [1].

Today pharmacological agents have been used for the prevention and treatment of shivering. A wide variety of agents with the different mechanism of action is available for use $[1,3,7]$, but unfortunately there is no gold-standard drug for the treatment of postoperative shivering and the relative efficiency of pharmacological intervention to prevent this phenomenon is not well understood [3].

Intravenous administration of drugs including magnesium sulfate, clonidine, opioids, physostigmine, ondansetron and ketanserin has been suggested for treatment of shivering [8-11]. The opioid, fentanyl, is known to affect the normed physiologic response to hypothermia, thus it can reduce the occurrence of shivering but, because of some side effect of intravenous opioids for management of shivering [1] today, injection of opioids into the subarachnoid space has been used specially for prevention of shivering after cesarean section. Prevention of shivering rather than treatment after its onset and, nonadministration of intravenous opioids to a patient due to possibility of inducing nausea and vomiting were reported as two advantages of using opioids administered by this route [1]. 


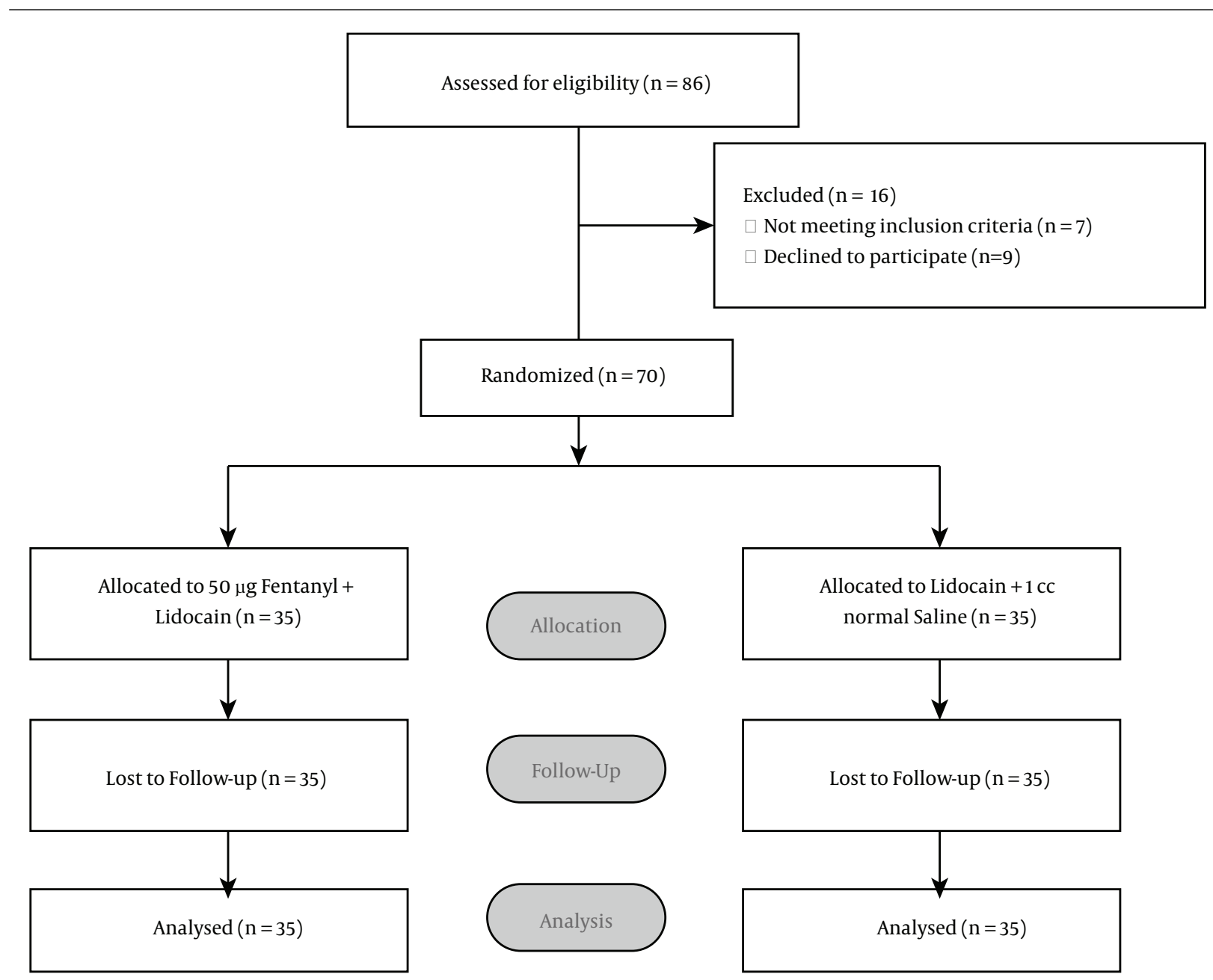

Figure 1. Flowchart Showing Participants and Group Disposition

Table 3. Incidence of Spinal Side Effect

\begin{tabular}{lccc}
\hline Side Effects & & Group & \multicolumn{2}{c}{ P Value } \\
\cline { 2 - 4 } & Lidocaine & Lidocaine+ Fentanyl & Total \\
\hline Headache & $1(2 / 85)$ & $3(8 / 55)$ & $4(5 / 71)$ \\
Nausea & $2(5 / 70)$ & $2(5 / 70)$ & $4(5 / 71)$ \\
Vomiting & $1(2 / 85)$ & $2(5 / 70)$ & $3(4 / 28)$ \\
Total & $4(11 / 40)$ & $7(19 / 95)$ & $11(15 / 7)$ \\
\hline
\end{tabular}

When opioid is administered in the subarachnoid space, it can act in non-specific sites of white matter or specific receptors in the dorsal horn of the spinal cord. There is also the rostral redistribution to cerebrospinal fluid, a certain amount of the drug diffuses into the epidural space and conveyed to the venous system. The clinical effects observed in patients are the result of these three routes of dis- tribution [2].

Among opioids meperidine seems to be most effective when administer intravenously, but it is controversial when we used them intrathecally. There are some studies about the intrathecal administration of meperidine whit different doses. Intrathecal meperidine $0.2 \mathrm{mg} / \mathrm{kg}$ associated with hyperbaric lidocaine $0.75 \%$ was effective in re- 


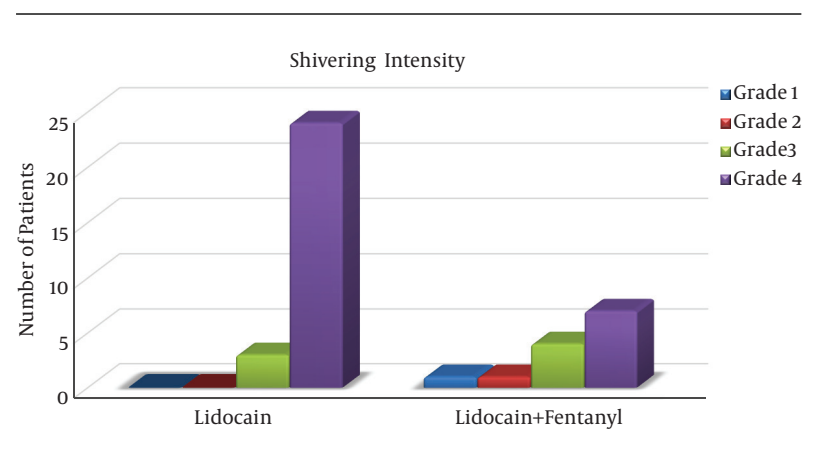

Figure 2. Severity of Shivering

ducing the incidence and intensity of shivering after cesarean section [12]. Another study was performed to compare the effect of different doses of intrathecal meperidine on the incidence and intensity of shivering and other sideeffects after spinal anesthesia for cesarean delivery. They used $0.2,0.3$ and $0.4 \mathrm{mg} / \mathrm{kg}$ of meperidine, and find that the high dose of intrathecal meperidine is effective in reducing the incidence and intensity of shivering associated with spinal anesthesia for cesarean delivery but the high incidence of nausea and vomiting is unpleasant for the patient and can be a major problem with a high dose of meperdine [13].

Fentanyl is a highly ionized, lipophilic $\mu$ receptor agonist that provide faster onset of action (5 - 10 minutes) but, with shorter duration of action ( $4-6$ hours). When it is administered intrathecally, the unionized component is rapidly transferred into the spinal cord and affect afferent thermal inputs at the spinal cord [14].

Intrathecal $0.2 \mathrm{mg} / \mathrm{kg}$ meperidine versus $20 \mu \mathrm{g}$ intrathecal fentanyl for prophylaxis of shivering in lower limb orthopedic surgeries under spinal anesthesia, show that total incidence and intensity of shivering was similar between groups F and $\mathrm{M}$ [15].

The present study was designed by intrathecal $50 \mu \mathrm{g}$ $(1 \mathrm{~mL})$ fentanyl for prophylaxis of post spinal shivering, to detect the efficiency and complication of this high dose fentanyl, because there is not enough study about the fentanyl different doses and practically more simple calculation and injection (as $1 \mathrm{~mL}$ fentanyl is equal to $50 \mu \mathrm{g}$ fentanyl) and for detection if this higher dose is more effective in reducing the incidence and intensity of shivering associated with spinal anesthesia. Also, we test this dose on the abdominal hysterectomy cases, because of the other studies were done on cesarean section almost.

Chow et al. study showed the administration of small dose $(12.5 \mu \mathrm{g})$ of intrathecal fentanyl had significant influence on incidence and severity of shivering during transurethral resection of prostate under spinal anesthe- sia. (65.8\% in control group and 12.2 in the study group) [16].

Techanivate et al. study showed intrathecal fentanyl 20 $\mu \mathrm{g}$ added to hyperbaric lidocaine plus Morphine can reduce the incidence and severity of shivering without increasing other side effects in cesarean section [17]. In another study Techanivate et al. reported that intrathecal 20 $\mu \mathrm{g}$ fentanyl significantly improved the quality of analgesia and the incidence of shivering in group $\mathrm{F}$ was significantly lower than group S (35\%.vs.70\%; P 0.023) [18].

Our results are in agreement with the data found in these studies but we had a $40 \%$ reduction in shivering incidence. It seems that usage of $50 \mu \mathrm{g}(1 \mathrm{~mL})$ intrathecal fentanyl in our study had benefits without additional side effects. but our results in comparison with Sadegh et al. study is different, they added $25 \mu \mathrm{g}$ fentanyl to lidocaine for cesarean section and they revealed that $25 \mu \mathrm{g}$ fentanyl can reduce the incidence and severity of shivering about $65 \%$, that is very higher than our results [14].

These differences may be due to environmental factor, as like as operation room temperature and racial differences or surgery type.

\subsection{Conclusions}

The present study suggests that the addition of $50 \mu \mathrm{g}$ $(1 \mathrm{~mL})$ fentanyl to $75 \mathrm{mg}$ of hyperbaric $5 \%$ lidocaine during spinal anesthesia for hysterectomy provides a decrease in the incidence of shivering in the immediate postoperative period up to two hours, without any adverse effect. However there are some controversies about the optimal effective and safe dose of intrathecal fentanyl, thus further studies are warranted to determine the optimal dose of Fentanyl for clinical use.

\section{Acknowledgments}

We would like to thank Arash research development center for contribution in preparation of this article. This research was recorded in Zahedan University of Medical Science with number of 1149. Dr. Maziar Mahjoubifard and Dr. Masoomeh Nataj-Majd were the main executers of the study.

\section{Footnotes}

Authors' Contribution: Maziar Mahjoubifard and Masoomeh Nataj-Majd designed and performed the study. Somaye Sadat Heidary analyzed the data and edited the manuscript. Nariman Mahjoubifard contributed in manuscript editing.

Conflict of Interest: Authors have no conflicts of interest. 
Funding/Support: Zahedan University of Medical Science.

\section{References}

1. Barash PG. Clinical anesthesia. Lippincott Williams \& Wilkins; 2009.

2. Locks GF. Incidence of shivering after cesarean section under spinal anesthesia with or without intrathecal sufentanil: a randomized study. Revista brasileira de anestesiologia. 2012;62(5):680-4.

3. Kranke P, Eberhart LH, Roewer N, Tramer MR. Single-dose parenteral pharmacological interventions for the prevention of postoperative shivering: a quantitative systematic review of randomized controlled trials. Anesth Analg. 2004;99(3):718-27. doi: 10.1213/01.ANE.0000130589.00098.CD. [PubMed: 15333401] table of contents.

4. Horn EP, Werner C, Sessler DI, Steinfath M, Schulte am Esch J. Late intraoperative clonidine administration prevents postanesthetic shivering after total intravenous or volatile anesthesia. Anesth Analg. 1997;84(3):613-7. [PubMed: 9052312].

5. Abdelrahman RS. Prevention of shivering during regional anesthesia: Comparison of midazolam, midazolam plus ketamine, tramadol, and tramadol plus ketamine. Life Sci J. 2012;9(2):132-9.

6. Honarmand A, Safavi MR. Comparison of prophylactic use of midazolam, ketamine, and ketamine plus midazolam for prevention of shivering during regional anaesthesia: a randomized doubleblind placebo controlled trial. Br J Anaesth. 2008;101(4):557-62. doi: 10.1093/bja/aen205. [PubMed: 18621986].

7. Piper SN, Maleck WH, Boldt J, Suttner SW, Schmidt CC, Reich DG. A comparison of urapidil, clonidine, meperidine and placebo in preventing postanesthetic shivering. Anesth Analg. 2000;90(4):954-7. [PubMed: 10735806].

8. Rastegarian A, Ghobadifar MA, Kargar H, Mosallanezhad Z. Intrathecal Meperidine Plus Lidocaine for Prevention of Shivering during Cesarean Section. Korean J Pain. 2013;26(4):379-86. doi: 10.3344/kjp.2013.26.4.379. [PubMed: 24156005].
9. Alfonsi P, Hongnat JM, Lebrault C, Chauvin M. The effects of pethidine, fentanyl and lignocaine on postanaesthetic shivering. Anaesthesia. 1995;50(3):214-7. [PubMed: 7717486].

10. Alfonsi P, Sessler DI, Du Manoir B, Levron JC, Le Moing JP, Chauvin M. The effects of meperidine and sufentanil on the shivering threshold in postoperative patients. pascal.alfonsi@apr.ap-hop-paris.fr. Anesthesiology. 1998;89(1):43-8. [PubMed: 9667292].

11. Marashi SM, Soltani-Omid S, Soltani Mohammadi S, Aghajani Y, Movafegh A. Comparing Two Different Doses of Intravenous Ondansetron With Placebo on Attenuation of Spinal-induced Hypotension and Shivering. Anesth Pain Med. 2014;4(2):e12055. doi: 10.5812/aapm.12055. [PubMed: 24790900].

12. Roy JD, Girard M, Drolet P. Intrathecal meperidine decreases shivering during cesarean delivery under spinal anesthesia. Anesth Analg. 2004;98(1):230-4. [PubMed: 14693625] table of contents.

13. Anaraki AN, Mirzaei K. The Effect of Different Intrathecal Doses of Meperidine on Shivering during Delivery Under Spinal Anesthesia. Int JPrev Med. 2012;3(10):706-12. [PubMed: 23112897].

14. Sadegh A, Tazeh-Kand NF, Eslami B. Intrathecal fentanyl for prevention of shivering in spinal anesthesia in cesarean section. Med J Islam Repub Iran. 2012;26(2):85-9. [PubMed: 23483276].

15. Safavi M, Honarmand A, Rahmanikhah E, Badiei S, Attari M. Intrathecal Meperidine versus intrathecal Fentanyl for prevention of shivering in lower limb orthopedic surgeries under spinal anesthesia: A randomized double-blind placebo-controlled trial.J Res Pharm Pract. 2014;3(4):137-41. doi: 10.4103/2279-042X.145390. [PubMed: 25535622].

16. Chow TC, Cho PH. [The influence of small dose intrathecal fentanyl on shivering during transurethral resection of prostate under spinal anesthesia]. Acta Anaesthesiol Sin. 1994;32(3):165-70. [PubMed: 7921861].

17. Techanivate A, Rodanant O, Tachawattanawisal W, Somsiri T. Intrathecal fentanyl for prevention of shivering in cesarean section. J Med Assoc Thai. 2005;88(9):1214-21. [PubMed: 16536107].

18. Techanivate A, Urusopone P, Kiatgungwanglia P, Kosawiboonpol R. Intrathecal fentanyl in spinal anesthesia for appendectomy.J Med Assoc Thai. 2004;87(5):525-30. [PubMed: 15222523]. 